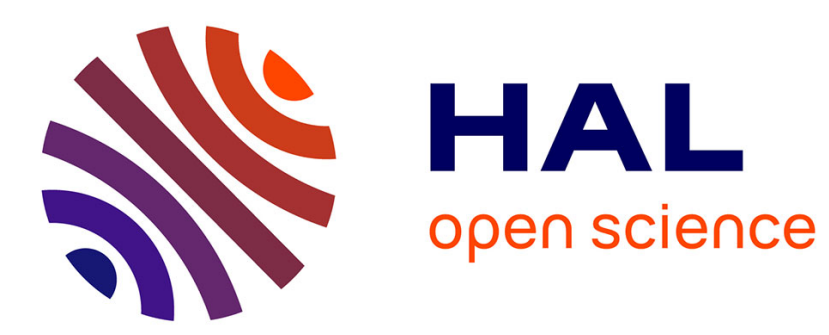

\title{
Sensitive response of sediment-grown Myriophyllum spicatum L. to arsenic pollution under different CO2 availability
}

Elisabeth M. Gross, Andréïna Nuttens, Paroshin Darya, Andreas Hussner

\section{- To cite this version:}

Elisabeth M. Gross, Andréïna Nuttens, Paroshin Darya, Andreas Hussner. Sensitive response of sediment-grown Myriophyllum spicatum L. to arsenic pollution under different CO2 availability. Hydrobiologia, 2018, 812 (1), pp.177-191. 10.1007/s10750-016-2956-7 . hal-02088981

\section{HAL Id: hal-02088981 \\ https://hal.univ-lorraine.fr/hal-02088981}

Submitted on 30 Apr 2021

HAL is a multi-disciplinary open access archive for the deposit and dissemination of scientific research documents, whether they are published or not. The documents may come from teaching and research institutions in France or abroad, or from public or private research centers.
L'archive ouverte pluridisciplinaire HAL, est destinée au dépôt et à la diffusion de documents scientifiques de niveau recherche, publiés ou non, émanant des établissements d'enseignement et de recherche français ou étrangers, des laboratoires publics ou privés. 
Published in Hydrobiologia - DOI 10.1007/s10750-016-2956-7

2

3

4

5

6

7

8

9 Elisabeth M. Gross ${ }^{1,2, *}$, Andréïna Nuttens ${ }^{1,2}$, Darya Paroshin ${ }^{1,2} \&$ Andreas Hussner ${ }^{3}$

\section{arsenic pollution under different $\mathrm{CO}_{2}$ availability \\ Sensitive response of sediment-grown Myriophyllum spicatum L. to}

10

$11{ }^{1}$ Université de Lorraine, LIEC UMR 7360 CNRS, Rue Général Delestraint, Bâtiment IBISE, 12 F-57070 Metz, France.

13 2 LTER-”Zone Atelier Moselle”, LIEC UMR 7360 CNRS, Rue Général Delestraint, Bâtiment 14 IBISE, F-57070 Metz, France.

$15{ }^{3}$ Institute of Botany, Heinrich-Heine-Universität Düsseldorf, Geb. 26.13.O2, Universitätsstr.

16 1, D-40225 Düsseldorf, Germany

17 * Corresponding author: gross5@univ-lorraine.fr; Tel.: +33 3873786 26; Fax +33 38737

$18 \quad 8512$ 
Aquatic plants may face resource constraints or anthropogenic pollution, and effects might be heightened under multiple stress conditions. We investigated if arsenate effects on Myriophyllum spicatum L. would be stronger under $\mathrm{CO}_{2}$ limitation and low phosphorus availability. In a factorial design, we exposed sediment-grown plants to either $\mathrm{CO}_{2}$ (high carbon or HC) or bicarbonate (low carbon or LC) and four levels of arsenate. We observed strong effects of arsenate exposure on growth, biomass allocation (leaf, stem and root mass fractions), pigments and phenolic compounds. $\mathrm{CO}_{2}$ availability strongly affected the content in phenolic compounds and a few other response variables, yet overall effects were less pronounced than expected. Strong interactive effects of $\mathrm{CO}_{2}$ availability and arsenic concentration were only observed for carotenoids, the carotenoid/chlorophyll ratio and phenolic compounds in leaves. Only the carbon content declined with increasing arsenic concentration, otherwise leaf elemental content and stoichiometry were not affected by arsenic or $\mathrm{CO}_{2}$ availability, suggesting that plants strived to maintain leaf functions. The observed effects on biomass allocation and plant quality, specifically elemental stoichiometry and phenolic compounds content of $M$. spicatum not only show direct changes in plant performance but suggest also indirect effects on ecological interactions such as competition or herbivory.

Keywords: Submerged macrophyte, Trace metal, Element pollution, OECD test guideline, aquatic ecotoxicology, $\mathrm{CO}_{2}$-based growth and physiology 


\section{Introduction}

Multiple stress scenarios are gaining focus both in ecology and ecotoxicology as we are facing effects at the global, regional and local scale, strongly enhanced by anthropogenic activities (Meybeck 2004; Segner et al. 2014). Since the response to a combination of stressors might be specific for a certain type or group of organisms (Segner et al. 2014), we need to understand the reaction of key organisms, such as those used in environmental risk assessment. The rooted submerged macrophyte $M$. spicatum is now used as OECD (Organisation for Economic Co-operation and Development) test organism because it allows testing for both sediment and water exposure to anthropogenic pollutants (OECD 2014).

While normalized test systems in ecotoxicology strive for optimal growth (see details on the OECD TG 239 for sediment grown M. spicatum below in materials and methods), resource availability are known to affect plant growth and physiology (Hussner \& Jahns 2015), and might thus also be involved in the response to pollution stress. Submerged macrophytes, such as M. spicatum, can take up nutrients via roots or shoots, but root uptake is the primary pathway (Grace \& Wetzel 1978; Smith \& Barko 1990). While excess or limiting nutrient amounts can be a constraint for submerged macrophytes, the availability of $\mathrm{CO}_{2}$ can even be more restraining, as $\mathrm{CO}_{2}$ diffusion is much slower in stagnant water, and the availability depends on the $\mathrm{pH}$ and total dissolved inorganic carbon (DIC) availability (Hussner \& Jahns 2015). Although the growth of M. spicatum is enhanced in alkaline lakes (Smith \& Barko 1990), $\mathrm{CO}_{2}$ compensation points are lower than those for $\mathrm{HCO}_{3}{ }^{-}$(Grace \& Wetzel 1978).

The genus Myriophyllum is known to accumulate trace metal elements, but this does not exclude negative effects on plant growth and physiology (e.g., Harguinteguy et al. 2015; Robinson et al. 2006). Arsenic is a trace metal element often found in aquatic systems 
resulting from geochemical or anthropogenic processes. The New Zealand M. propinquum in the Taupo Volcanic area hyperaccumulated $2101 \mathrm{mg}$ [As] per kg dry mass (Robinson et al. 2006), and the North American M. sibiricum Kom. (syn. M. exalbescence Fernald) from a lake polluted by mine tailings accumulated more than $140 \mathrm{mg} \mathrm{kg}^{-1}$ [As] in its dry mass (Dushenko et al. 1995). In freshwaters, arsenic occurs mainly as arsenate under oxygenic or arsenite under anoxic conditions (Rahman et al. 2012), and the adsorption of arsenic to sediments is influenced by metal oxides but also by carbonate and bicarbonate concentrations (Smedley \& Kinniburgh 2002).

Various environmental factors influence the uptake of arsenic by plants. Plants take up arsenate via the phosphate uptake transporter (Finnegan \& Chen 2012). In laboratory experiments, high phosphate availability reduced the arsenate uptake by Lemna minor (Mkandawire \& Dudel 2012) and rice (Geng et al. 2005). However, no relationship between in-situ phosphate availabiliy and arsenic uptake was observed for a range of submerged and emergent macrophytes in Canadian lakes (Dushenko et al. 1995). Under alkaline pH, the fern Pterris vittata contained less arsenic than under neutral $\mathrm{pH}$, but bicarbonate concentration in natural ranges (up to $2 \mathrm{mM}$ ) showed little effect on arsenic uptake by the plant (Guo et al. 2012). Yet, eutrophic conditions reduced the arsenate uptake by the congeneric $M$. alterniflorum, a species adapted to oligo-mesotrophic conditions (Krayem et al. 2016). The effect of alkalinity, and thus $\mathrm{pH}$ and $\mathrm{CO}_{2}$ availability, on the uptake of arsenic has, as far as we know, not yet been tested with submerged freshwater plants. In this context we performed our study, knowing that M. spicatum prefers meso- to eutrophic and alkaline environments. Environmental stressors and resource constraints can have a wide range of effects in plants. They may not only affect growth, but also morphological traits such as biomass allocation to leaves, shoots and roots or leaf dry matter content (LDMC), changes that may explain plant performance at the inter- and intraspecific level (Elger \& Willby 2003; Fornoff 
\& Gross 2014; Hussner \& Jahns 2015; Pérez-Harguindeguy et al. 2013) or physiological traits, such as pigment composition, changes in elemental stoichiometry (i.e. carbon, nitrogen and phosphorus content), and the production of defensive substances such as phenolic compounds (Fornoff \& Gross 2014; Gross 2003; Hussner et al. 2015; Hussner \& Jahns 2015). Phenolic compounds are widely involved in plant responses to abiotic and biotic stressors (Dixon \& Pavia 1995), and M. spicatum is a species well known for its high content in bioactive polyphenols acting against competitors and herbivores (Fornoff \& Gross 2014; Leu et al. 2002) but also varying depending on resource availability (Gross 2003). High $\mathrm{CO}_{2}$ availability increased the production of phenolic compounds in terrestrial plants (Hartley et al. 2000), and trace metal elements affected the content of phenolic compounds (Lavid et al. 2001), possibly because of oxidative stress responses (Waśkiewicz et al. 2014).

Since the availability of $\mathrm{CO}_{2}$ is a major constraint for submerged macrophytes, and because of the potential impact of $\mathrm{pH}$, bicarbonate and nutrient availability on the effect of arsenic on aquatic plants, we used a factorial design experiment to test the effects of arsenate under different $\mathrm{CO}_{2}$ availability and at low phosphorus availability on M. spicatum. Our hypotheses were that 1) environmentally relevant arsenic concentrations would negatively affect growth and physiological response variables (i.e. "endpoints" sensu ecotoxicological test protocols, e.g., OECD 2014) in M. spicatum, 2) effects would be enhanced at high pH reflecting low $\mathrm{CO}_{2}$ availability, and 3) changes in morphological and physiological plant traits of M. spicatum reflect specific responses towards a certain combination of stressors. We included growth, pigment content, plant stoichiometry, and the content in phenolic compounds as response variables to see if these "endpoints" are useful for predicting potential ecological and ecosystem effects caused by multiple environmental stressors. 
Cultivation of plants and experimental set-up

We performed our experiment in a plant-water-sediment test system modified after the currently accepted new OECD test guideline for the rooted aquatic plant $M$. spicatum (OECD 2014). This test system uses 2 L glass beakers, a sediment mixed from sand, kaolin, white peat and calcium carbonate $(74 / 20 / 5 / 1 \%$ on a weight basis $)$, amended with rather high concentrations of nutrients (each $200 \mathrm{mg}$ of ammonium chloride and sodium phosphate per $\mathrm{kg}$ of dry sediment), and a water column based on the so called Smart \& Barko medium (Smart \& Barko 1985), a mineral solution rich in calcium chloride, magnesium sulphate, potassiumand sodium bicarbonate, but free of nitrogen and phosphorus. In a typical set-up, three shoots of M. spicatum per beaker grow without any aeration for 14 days. For our purposes, we modified container size, shoot density, nutrient provision and $\mathrm{CO}_{2}$ availability.

Approximately $4 \mathrm{~cm}$ long apical shoot sections of $M$. spicatum from axenic cultures maintained in the laboratory of EMG (Gross 2003) were adapted during two weeks to Smart \& Barko medium (Smart \& Barko 1985) supplemented initially with $143 \mu \mathrm{M} \mathrm{N}-\mathrm{NO}_{3}$ and 2.6 $\mu \mathrm{M} \mathrm{P}_{-} \mathrm{PO}_{4}$ as potassium salts, and after one week with half the dose of $\mathrm{N}$ and $\mathrm{P}$. This resulted in a molar N:P ratio of 55:1, as we intended to apply a slight phosphorus limitation (Güsewell \& Koerselman 2002) to enhance effects of arsenate. We applied the nutrients only to the water column, and not in the sediment to avoid direct competition with arsenate. For the sediment-based pre-culture lasting 5 days, shoots were planted in artificial sediment modified slightly from the OECD 239 test protocol (OECD 2014), omitting $\mathrm{CaCO}_{3}$ and nutrient additions, and only using 75\% sand, 20\% kaolin 5\% white peat. The water column consisted of Smart \& Barko (1985) solution amended with N and P as described above. 
$7 \mathrm{H}_{2} \mathrm{O}$ per kg dry sediment, mixed as aqueous solution with the wetted sediment to reach $20 \%$ water content. An equivalent of $200 \mathrm{~g}$ dry sediment was added to square plastic pots $(250 \mathrm{ml}$; $11 \times 7 \times 3 \mathrm{~cm} ; \mathrm{w} \times \mathrm{d} \times \mathrm{h})$, and one each was then placed in a 3 -L plastic container $(15 \times 11 \times$ $19 \mathrm{~cm} ; \mathrm{w} \times \mathrm{d} \times \mathrm{h}$ ). The total volume of medium added per container was $2.5 \mathrm{~L}$.

We set up 32 containers, 16 dedicated for each of the two different DIC conditions ( $\mathrm{HC}$ / high $\mathrm{CO}_{2}$ availability or $\mathrm{LC} /$ low $\mathrm{CO}_{2}$ availability/ dominance of $\mathrm{HCO}_{3}{ }^{-}$treatment), and four replicates for each [As] concentration (4 levels including control) and carbon condition. Half of the containers were filled with the standard Smart \& Barko solution at 0.85 mM DIC (LC treatment), the other half with only $0.45 \mathrm{mM}$ DIC (HC treatment) but amended with $\mathrm{CO}_{2}$ aeration from a $\mathrm{CO}_{2}$ tank (50 1; $\mathrm{NE} 45$ - 99.995\%) via needle valves to yield final DIC concentrations of $0.8-0.9 \mathrm{mM}$. The LC treatments were only bubbled with air to allow gas exchange with the atmosphere. The addition of $\mathrm{CO}_{2}$ to the $\mathrm{HC}$ treatments shifted the total DIC concentration to $0.8-0.9 \mathrm{mM}$ (Hussner \& Jahns 2015). Thus, different proportions of $\mathrm{CO}_{2}$ and $\mathrm{HCO}_{3}{ }^{-}$were available in the $\mathrm{HC}$ and $\mathrm{LC}$ treatments, as quantified by standard methods (see detailed description in Hussner \& Jahns, 2015, and yielding pH values of $6.8 \pm$ 0.2 and $8.2 \pm 0.2$ in the $\mathrm{HC}$ and LC treatments, respectively). All containers were placed in a water bath at $22 \pm 2{ }^{\circ} \mathrm{C}$ and $120( \pm 15 \%) \mu \mathrm{mol}$ photons $\mathrm{m}^{-2} \mathrm{~s}^{-1}$ illumination by OSRAM SubstiTUBE LED light tubes (ST8-HV4-170-840) at a 16/8 h L/D photoperiod.

Each pot was planted with two shoots of M. spicatum. Shoots were selected from the pre-cultures to have a shoot length between 6 and $14 \mathrm{~cm}(9.0 \pm 1.8 \mathrm{~cm}$, mean $\pm 1 \mathrm{SD})$ and well developed roots of approximately 1 to $2 \mathrm{~cm}$ length. Because shoots differed much in length, we decided do use each one larger shoot $(\mathrm{A} ; 8.7-14 \mathrm{~cm})$ and one smaller shoot $(\mathrm{B} ; 6$ $-11 \mathrm{~cm}$ ) per container. Before planting, each shoot was carefully blotted dry to take the initial fresh weight $(0.19 \pm 0.06 \mathrm{~g}$; equivalent to $0.014 \pm 0.004 \mathrm{~g}$ dry mass based on dry-to-fresh 
mass calibration of 10 control shoots) before planting. Preliminary experiments had shown that carefully blotting-to-dry would not harm plant development. Care was taken to distribute shoots evenly among all containers. No difference in initial total length or fresh mass for the different treatments and containers existed (1-way ANOVA, $\mathrm{F}<1.22 ; \mathrm{P}>0.33$ ).

Maintenance and end of experiment

The experiment was run for 14 days, and $\mathrm{pH}$ and water level of all containers was controlled and eventually adjusted daily, or once every two days during the weekend. We occasionally measured oxygen content around midday, and found all containers at or above $100 \%$ saturation, indicating ongoing photosynthetic activity of the plants. At the end of the experiment, we carefully removed the two shoots per container, and measured main shoot length, root length and eventual side shoot length, as well as total fresh mass. Each shoot was photographed to document its appearance. Shoot A was dissected into root, shoot and leaf biomass, each fraction was placed individually into pre-weighted tubes to determine fresh mass, and shock frozen in liquid nitrogen. Shoot B was left intact and whole plants were shock frozen using liquid nitrogen. All frozen samples were freeze-dried for $24 \mathrm{~h}$, providing individual total shoot or root, stem, and leaf dry mass. From leaves, we calculated for shoot A the respective leaf mass fractions $(\mathrm{LMF}=$ leaf dry mass/total dry mass or LMF-a = leaf dry mass/ leaf+stem dry mass; the latter to account for aboveground biomass), as well as stem and root mass fractions $(\mathrm{SMF}=$ stem dry mass/total dry mass; $\mathrm{RMF}=$ root dry mass/total dry mass). For all samples, we calculated also the respective dry matter content (DMC) for total shoots or plant organs (leaf, stem and root dry matter content as LDMC, SDMC and RDMC, respectively) based on the respective ratios between dry and fresh mass. 

length (RGR-L) based on the equation $\mathrm{RGR}=\left(\ln \mathrm{W}_{\mathrm{f}}-\ln \mathrm{W}_{\mathrm{i}}\right) / \mathrm{d}$ with $\mathrm{W}_{\mathrm{f}}$ the end value, $\mathrm{W}_{\mathrm{i}}$ the initial value and $d$ the time in days.

Chemical analyses

Inorganic nutrients in the water column $\left(\mathrm{N}-\mathrm{NO}_{3}\right.$ and $\left.\mathrm{P}-\mathrm{PO}_{4}\right)$ were measured at the end of the experiment using ion chromatography (ICS-1100, Thermo-Fisher Scientific) and spectrophotometry following standard procedures (AFNOR 1990). Arsenic in the sediment was analysed after mineralization in $35 \%$ ultrapure $\mathrm{HNO}_{3}$ for $24 \mathrm{~h}$. Arsenic in the mineralized sediment samples and the water samples were then quantified by atomic absorption spectroscopy (AAS; Perkin-Elmer, AAnalyst 100).

Dry biomass samples were ground to a fine powder using a Fritsch pulverisette 23 ball mill before use in chemical analyses. All sample mass data are approximate values, the exact mass for each sample was determined with a Sartorius MC2 ultra-microbalance at a precision of $10 \mu \mathrm{g}$. Elemental content for carbon $(\mathrm{C})$, nitrogen $(\mathrm{N})$ and phosphorus $(\mathrm{P})$ were determined in leaves from plant $\mathrm{A}$. The content in $\mathrm{C}$ and $\mathrm{N}$ were determined based on analyses of subsamples of $1 \mathrm{mg}$ encapsulated in tin containers in a Carlo-ERBA Na $2100 \mathrm{CE}$ elemental analyser. P was determined according to AFNOR (1990) using alkaline digestion (1 N NaOH and $0.45 \mathrm{M} \mathrm{Na}_{2} \mathrm{~S}_{2} \mathrm{O}_{8}$ ) of $1 \mathrm{mg}$ samples for $2 \mathrm{~h}$ at $120^{\circ} \mathrm{C}$ and 1 bar followed by spectrophotometric quantification in an automated analyser (Konelab 420-XTi, Thermo Fischer Scientific). methods described in Fornoff \& Gross (2014). All measurements were made in a Varian Cary 50 spectrophotometer. Chlorophyll was extracted from $0.5 \mathrm{mg}$ samples extracted in $1 \mathrm{ml}$ 
acetone/TRIS-hydrochloric acid-buffer $(0.1 \mathrm{M}), 8 / 2(\mathrm{v} / \mathrm{v}) ; \mathrm{pH} 7.8$, for $2 \mathrm{~h}$ at $16{ }^{\circ} \mathrm{C}$. The absorbance was measured at 470, 664 and $647 \mathrm{~nm}$ to calculate the carotenoid, the chlorophyll $a$ and $b$ content per extracted biomass based on the equations provided by Lichtenthaler \& Buschmann (2001). Anthocyanin was extracted with acidified methanol (methanol/water/hydrochloric acid $37 \%, 80 / 20 / 1[\mathrm{v} / \mathrm{v} / \mathrm{v}]$ ) from $1 \mathrm{mg}$ samples in $1 \mathrm{ml}$ solvent for $2 \mathrm{~h}$ at $16{ }^{\circ} \mathrm{C}$. The absorbance at 532 and $653 \mathrm{~nm}$ was used to calculate the anthocyanin content (cyanidin, the major anthocyanin found in Myriophyllum spp. (Reznik \& Neuhausel 1959) based on the formula developed from Murray \& Hackett (1991): Anthocyanin $[\mathrm{mg} / \mathrm{g}]=$ $(($ A $532 \mathrm{~nm})-(0.24 *$ A $653 \mathrm{~nm})) /(30 / 287.24 * \mathrm{~m}) ;$ with $\mathrm{A}=$ absorbance at the respective wave length and $\mathrm{m}$ the exact dry mass of the sample extracted in one $\mathrm{ml}$ solvent. Total phenolic compounds (TPC) were extracted in aqueous acetone $(50 / 50[\mathrm{v} / \mathrm{v}] ; 1 \mathrm{mg}$ sample in 1 ml solvent) followed by the Folin-Ciocalteau assay with tannic acid (no. 403040, batch 06817CJ; Sigma-Aldrich) as standard, following methods described in Fornoff \& Gross (2014).

\section{Statistical analyses}

Data were analysed using R Studio (2015). Homoscedasticity and normality were verified respectively by the Levene and Shapiro-Wilk tests, and if needed, data were log or 1/x transformed to ensure normality and equal variance. Two-way ANOVAs with carbon and arsenic condition as fixed factors were calculated for all response variables using a probability threshold of $p \leq 0.05$, followed by Tukey post-hoc tests in case of significant differences among treatments. A Principal component analysis (PCA) was performed on the full set of endpoints except global DMC to visualize differences according to the experimental conditions using FactoMineR (Lê et al. 2008). The contribution of each variable (endpoint) 
for the different axes (i.e. the quality of representation of endpoints upon axes) was computed and called column inertia.

\section{Results}

Sediment and water column

The $\mathrm{pH}$ in the high and low $\mathrm{CO}_{2}$ treatments stayed constant at the values provided in Material and Methods due to the continuous aeration ( $\mathrm{LC}$ treatment) and $\mathrm{CO}_{2}$ aeration ( $\mathrm{HC}$ treatment). Oxygen concentrations remained near or slightly above $100 \%$, also due to the aeration-induced turbulence. No visual algal growth in the water column was observed, only occasionally we found some algae growing on the sediment, but not on the plants. Reference plants which were visibly free from epiphytes are documented in Supplementary Figure A1. Plants had absorbed about $36 \%$ of the added $\mathrm{N}-\mathrm{NO}_{3}$ and $22 \%$ of the added $\mathrm{P}-\mathrm{PO}_{4}$ (data not shown).

At the end of the experiment, we typically recovered $75-150 \%$ of the initially applied arsenic in the containers, when combining concentrations found in sediment and water (Table 1). Part of the arsenic had leached into the water column, and this effect increased with increasing initial sediment arsenic concentrations. Controls exhibited low concentrations of arsenic, possibly leaching from background levels in sediments. In the low arsenic treatment (1.44 ppm) we found about $50 \%$ higher concentrations than intended, possibly caused by sediment background levels. While the arsenic concentrations for the levels 7.2 and $36 \mathrm{ppm}$ in the $\mathrm{HC}$ treatments were close to the intended values with 110 and $100 \%$ measured concentrations, they were significantly lower in the LC treatments, with only 85 and $76 \%$. Thus, recovery of arsenic was significantly lower in the LC treatments (Tukey post-hoc test, $p$ $<0.05)$. 
258

259

260

261

262

263

264

265

266

267

268

269

270

271

272

273

274

275

276

277

278

279

Plant responses

$\mathrm{CO}_{2}$ availability and arsenic concentrations affected growth, plant traits, and plant physiology of M. spicatum. In general, arsenic effects were pronounced at 7.2 and $36 \mathrm{ppm}$ [As] in sediment, while high or low $\mathrm{CO}_{2}$ availability affected only a few response variables, and almost no interactive effects between factors were observed (Table 2, referring also to all response variables outlined in detail below).

A - Effects on the growth of shoots A and B

The growth of M. spicatum based on of length, fresh and dry weight was strongly influenced by arsenic, while low $\mathrm{CO}_{2}$ availability only significantly reduced length-based growth, with marginal effects on biomass-based growth parameters (RGR-L, RGR-fm and RGR-dm). The dry matter content (DMC) increased by about $50 \%$ at arsenic concentrations of 7.2 and 36 ppm, resulting in somewhat weaker effects on dry mass-related growth (Fig. 1 A-C).

B - Effects on biomass allocation of shoot A

Arsenic and to a lesser extend $\mathrm{CO}_{2}$ availability affected the biomass allocation to leaves, stems and roots in M. spicatum (Fig. 2). This resulted in differences in the respective mass fractions of leaves (LMF), stems (SMF) or roots (RMF). With increasing arsenic concentrations, RMF declined while stems got thicker resulting in a higher SMF. Under low $\mathrm{CO}_{2}$ availability, the allocation to leaves increased while that to stems decreased. For leaves, we calculated two indices: One dividing leaf dry mass by total biomass (LMF), and one using 
only the aboveground biomass (LMF-a). Since root biomass declined strongly with increasing arsenic, the effect at the whole plant biomass on LMF was rather weak, and no differences between treatments were found. When roots were omitted in the calculation, the LMF-a declined with increasing arsenic concentrations, and that this effect was enhanced in LC treatments. At the two highest arsenic concentrations, the dry matter content (DMC) increased for all plant organs in shoot A (leaves - LDMC, stems - SDMC and roots - RDMC) while high $\mathrm{CO}_{2}$ availability only increased the RDMC.

$\mathrm{C}-$ Effects on pigment and phenolic compound content in leaves of shoot $\mathrm{A}$ Effects on pigments in leaves are shown in Fig. 3A-D. Total chlorophyll content declined with increasing arsenic concentration, but the chlorophyll $\mathrm{a} / \mathrm{b}$ ratio did not differ between treatments. A strong interaction between arsenic concentration and $\mathrm{CO}_{2}$ availability was observed for the carotenoid concentration, which specifically declined at high $\mathrm{CO}_{2}$ availability and higher arsenic concentrations. Subsequently, also the ratio of carotenoids to total chlorophyll exhibited a strong interaction effect between arsenic concentration and $\mathrm{CO}_{2}$ availability.

Anthocyanins (Fig. 4A) declined at low $\mathrm{CO}_{2}$ availability and higher arsenic concentrations in leaves, but we observed no arsenic-induced differences at high $\mathrm{CO}_{2}$ availability. The content in total phenolic compounds (TPC; Fig. 4B) in leaves A was strongly affected by $\mathrm{CO}_{2}$ availability and arsenic concentration, but with no clear pattern, thus resulting in strong interactive effects. While high $\mathrm{CO}_{2}$ availability increased the TPC in leaves, we observed no consistent trend with increasing arsenic concentrations. Only the leaves from the LC treatment had higher TPC at higher arsenic concentrations. 
D - Effects on elemental stoichiometry in leaves from shoot A (Fig. 5)

Both factors, arsenic concentration and $\mathrm{CO}_{2}$ availability, had only slight effects on the elemental composition of carbon, nitrogen and phosphorus in leaves. With higher arsenic concentrations, the $\mathrm{C}$ content declined in leaves, irrespective of $\mathrm{CO}_{2}$ availability. Only marginal effects were observed for nitrogen and phosphorus. Leaves in the LC treatment at higher arsenic concentrations had a slightly lower $\mathrm{N}$ content, and the phosphorus content was not affected by arsenic and only marginally reduced by low $\mathrm{CO}_{2}$ availability. Overall leaf stoichiometry was not affected, as neither $\mathrm{CO}_{2}$ availability nor arsenic concentration affected the $\mathrm{C}: \mathrm{N}, \mathrm{C}: \mathrm{P}$ or $\mathrm{N}: \mathrm{P}$ molar ratio.

\section{E - Overall effects on plant performance (Fig. 6)}

The principal component analysis (PCA) on the whole set of endpoints and for the different treatment combinations showed distinct differences between treatment combinations. Axes 1 and 2 explained 37.2 and $15.7 \%$ of the variance. The axes 3 and 4 added another 9.9 and $7.8 \%$ to explain in total more than $70 \%$ of the total variance. Differences between low ( 0 and $1.44 \mathrm{ppm}$ ) or high (7.2 and $36 \mathrm{ppm}$ ) levels of [As] in sediment were visible along axis 1 , while less pronounced differences based on $\mathrm{CO}_{2}$ availability were related to axis 2 . The correlation circle (Fig. 6A) shows the significant correlations for fresh mass based growth (RGR-fm), root mass fraction (RMF) and chlorophyll content (chl $a, \mathrm{chl} a+b$ ), and in opposite direction stem mass fraction (SMF) and the dry matter content of all plant organs, leaves, roots and stems (LDMC, RDMC, SDMC) with axis 1 . Axis 2 is mainly explained by phosphorus content $(\mathrm{P})$ and the resulting $\mathrm{C}: \mathrm{P}$ molar ratio, and to a lesser extent by the N:P molar ratio and pigment ratios (car/chl, chl $a / b$ ). 
Detailed correlation coefficients and associated P-values can be found in the Supplementary Material, Table A1.

\section{Discussion}

In a 14-day exposure to arsenate in combination with high or low $\mathrm{CO}_{2}$ availability we observed treatment-specific effects on the growth, biomass allocation and plant metabolism in the rooted, submerged macrophyte $M$. spicatum. In the following we will discuss our initial hypotheses in detail.

Hypothesis 1: Environmentally relevant arsenic concentrations negatively affect growth and physiological response variables in M. spicatum

Most selected endpoints measured in M. spicatum showed the effect of arsenic applied to the sediment. Negative effects on growth and physiology started at a nominal concentration of $7.2 \mathrm{ppm}$ arsenic applied to the sediments. This is a rather low concentration, and in the range of "normal", natural values found in lake or river sediments (Smedley \& Kinniburgh 2002). However, the observed effects might have been higher in our experiment because the applied arsenate is highly soluble, and diffused rapidly from the sediment to the overlying water column, as our measurements show (Table 1). Also under natural conditions, sediments and rocks release arsenic to the water column. Robinson et al. (2006) observed water concentrations up to $180 \mu \mathrm{g} \mathrm{l}^{-1}$ in the Taupo Volcanic Area, but in areas with no geochemical or anthropogenic sources for arsenic, concentrations are mostly below $10 \mu \mathrm{g}^{-1}$ (Smedley \& Kinniburgh 2002).

We could not assess the fate of arsenic accumulated in plant tissues or plant uptake as we only had limited biomass available (50 to $150 \mathrm{mg}$ per replicate, depending on treatment 
and used for all chemical analyses). Nevertheless, the negative effects already at 7.2 and 36 ppm nominal sediment concentrations suggest that at least part of the arsenic had been taken up by the plants, either from sediment or water. Laboratory studies showed growth reductions in M. propinquum from the Taupo Volcanic Zone rich in arsenic at about 170 to $290 \mu \mathrm{g} 1^{-1}$ (Robinson et al. 2006). In our study, first effects occurred at measured final concentrations of approximately $300 \mu \mathrm{g}^{-1}$ in water and $3.25 \mathrm{ppm}$ in sediment originally spiked with $7.2 \mathrm{ppm}$ [As]. No effects were observed in the control and the low arsenic treatment, although they contained some arsenic in water and sediment.

A remarkable finding is the strong increase in the dry matter content (DMC) of the whole shoots or in the different plant organs (leaves - LDMC, stems - SDMC, roots - RDMC) at higher arsenic concentrations. This indicates that plant physiology was altered, as plants had reduced water content and/or changed some metabolites or components, such as increased allocation to storage carbohydrates and starch (Hussner \& Jahns 2015). Exposure to arsenic also increased starch content in Ceratophyllum demersum due to negative effects on photosynthesis (Mishra et al. 2014), thus it is likely that the observed increase in DMC here is caused by starch accumulation.

Plant leaves, stems, roots, and tissue biomass ratios also changed following exposure to arsenic. Despite significant amounts of arsenic leaching into the water column, we observed a strong reduction in root mass, both absolute and relative to total biomass (root mass fraction / RMF), from above $15 \%$ to around $5 \%$ in high arsenic treatments. RMF provides comparable results to the frequently used root/shoot ratio, with the difference that the latter divides the root biomass only by the aboveground biomass, thus in our case the root/shoot ratio in the controls and low arsenic treatments would be approximately $20 \%$, a value comparable to that reported by Hussner \& Jahns (2015). 

controls (Fig. A1). This is a well described phenomenon for macrophytes growing in metal377 polluted sediments. The darkening results in part from iron plaques formed on the roots.

Many trace metal elements, including arsenic, bind to iron plaques on macrophyte roots (Taggart et al. 2009), and the magnitude of iron plaque formation on roots influences the accumulation of trace metal elements in aquatic plants (Tripathi et al. 2014). Stem appearance did not differ visually (Fig. A1), but the biomass allocation to stems (SMF) rose sharply with higher arsenic exposure, increasing from $25 \%$ up to $40 \%$ of the total biomass. We assume that plants used the stems to store arsenic and avoid negative effects on leaves.

The decline in chlorophyll $a$ and $b$ in leaves of plants exposed to higher arsenic concentrations is not unexpected, and has been observed in other plants exposed to arsenic or other trace metal elements. For example, negative effects on photosynthetic pigments have been observed in the floating fern Azolla filiculoides exposed to $60 \mu \mathrm{g} \mathrm{1^{-1 }} \mathrm{As}(\mathrm{V})$ (SánchezViveros et al. 2011). Overall we can confirm our first hypothesis that arsenic exposure at environmentally realistic concentrations caused strong effects on different growth and physiology related parameters in M. spicatum.

Hypothesis 2: Effects of arsenic exposure are enhanced at high $\mathrm{pH}$ and low $\mathrm{CO}_{2}$ availability Low $\mathrm{CO}_{2}$ availability caused much less, and usually less strong effects on the growth and physiology of M. spicatum, and only a few interactive effects between $\mathrm{CO}_{2}$ availability and arsenic exposure could be observed. High bicarbonate concentration in the medium together with a high $\mathrm{pH}$ had affected arsenic uptake in the fern Pteris vittata (Guo et al. 2012). Yet, we observed only little differences between the two carbon treatments for arsenic induced effects, and thus assume that the applied higher $\mathrm{pH}$ or lower $\mathrm{CO}_{2}$ availability, 
resulting in a higher bicarbonate concentration of the medium, might not have affected the bioavailability, or negative effects of arsenic on M. spicatum. Only length growth was significantly affected and mass-based growth rates declined only marginally. A much stronger effect of $\mathrm{CO}_{2}$ availability was observed on biomass allocation to leaves, stems and roots. We found an increase in RDMC in the high $\mathrm{CO}_{2}$ treatments, while Hussner \& Jahns (2015) found an increase in LDMC at high $\mathrm{CO}_{2}$ availability. Possibly the light intensity in our experiment was too low, as the effects were also reduced or not visible in the low light treatments of Hussner \& Jahns (2015). Leaf biomass increased (LMF-a and LMF) in the low $\mathrm{CO}_{2}$ treatments, and this can be seen in accompanying photographs (Fig. A1). We explicitly calculated both the LMF based on total biomass and that based only on aboveground biomass (LMF-a). While the former is commonly used as plant trait (Pérez-Harguindeguy et al. 2013), the strong changes in root biomass resulted in a higher significance when considering only the aboveground biomass for the calculation (LMF-a; Table 2). Our results indicate that plants in the low $\mathrm{CO}_{2}$ treatments invested more in leaf biomass to improve the diffusional dissolved inorganic carbon uptake (Eusebio Malheiro et al. 2013).

Except for a few cases, low $\mathrm{CO}_{2}$ availability has not enhanced negative effects of arsenic exposure on M. spicatum. This might be due to the less severe carbon limitation in our set-up that provided still some aeration and kept the $\mathrm{pH}$ at about 8.2. If the higher $\mathrm{pH}$ of 9 as observed in the new OECD TG 239 (OECD 214) would have stronger effects needs to be shown. Yet, effects with the fern Pteris vittata (Guo et al. 2012) were also only visible at rather high bicarbonate levels, and not in environmentally relevant ranges as used in our experiment. We thus cannot confirm our second hypothesis. 
Hypothesis 3: Changes in morphological and physiological traits of M. spicatum reflect specific responses towards a certain combination of stressors.

Although we could not confirm our second hypothesis, we think that our extended analysis of additional parameters provides a good picture of specific responses of $M$. spicatum to certain stressors. To achieve this we used morphological plant traits, such as the dry matter content (DMC) and mass fractions for leaves, stems and roots (LMF, SMF, RMF), or physiological traits such as the elemental composition and stoichiometry and the content in phenolic compounds. The principal component analysis shows (Fig. 6B) that for the two higher arsenic concentrations $\mathrm{CO}_{2}$ availability did make a difference in the overall plant response, based on individual endpoints, or response variables.

Only arsenic increased the DMC in M. spicatum, but an increase in DMC has several implications. From an ecological perspective, plants with a higher LDMC are less palatable to herbivores (Elger \& Willby 2003) and M. spicatum even increases the DMC of apical tissues when attacked by herbivores (Fornoff \& Gross 2014). With respect to common endpoints used in ecotoxicology, an increased DMC can mask effects on dry mass based yield or relative growth rate calculations. Our results show that effects based on dry mass (RGR-dm) were weaker than those based on fresh mass or total shoot length (RGR-fm; RGR-L). Arsenic is not the only pollutant causing this effect, as the herbicides metsulfuron-methyl (Cedergreen et al. 2004) and mesosulfuron-methyl previously showed no effects on dry-mass based growth estimations in M. spicatum, due to increases in DMC as we observed recently (Nuttens et al. 2016). From an ecotoxicological perspective, it seems thus prudent to select several growth endpoints to avoid the masking effect of increases in DMC on dry mass related results.

Changes in the proportion of leaf, stem and root biomass have ecological and ecotoxicological implications. From an autecological perspective, stronger stems can provide 
more stability and resistance to mechanical forces, but if this is at the expense of leaf biomass, plants will have less photosynthetic tissue and thus risk slower growth rates. The new test guideline for M. spicatum growing in a water-sediment set-up (OECD 2014) requires only evaluation of root development. Though it seems unlikely that all plant traits used here could be included for most normalized testing, the selection of additional endpoints would be quite useful for understanding processes at the plant level and implications in an ecological context. We found significant effects of both $\mathrm{CO}_{2}$ availability and arsenic, and interaction effects on levels of phenolic compounds in M. spicatum, suggesting that this endpoint is reacting strongly influenced by environmental conditions. A decline in phenolic compounds was found in A. filiculoides exposed to arsenic (Sánchez-Viveros et al. 2011), yet we observed either no effect on TPC (HC for leaves) or an increase (LC for leaves exposed to 7.2 or $36 \mathrm{ppm}$ [As]). Anthocyanin increased in Lemna exposed to water containing arsenic (Leao et al. 2014), but we observed a decline in anthocyanins. Phenolic compounds are ubiquitous in terrestrial and aquatic plants, but the relative content and composition can vary strongly depending on environmental conditions, and in response to a wide range of abiotic and biotic stressors (Dixon \& Pavia 1995; Gross \& Bakker 2012). We think that phenolic compounds are interesting indicators for environmental stressors acting on M. spicatum and other plants, and propose to have a more detailed look how they are modified e.g. by trace metal elements in combination with environmental conditions, and how this affects plant performance and biotic interactions.

Effects of $\mathrm{CO}_{2}$ availability and arsenic on elemental composition and plant stoichiometry were relatively low in M. spicatum leaves. We expected that increased arsenic concentration would reduce the uptake of phosphate, as had been observed for Lemna (Mkandawire \& Dudel 2012), but this effect was not found in leaves. The nitrogen content was slightly affected by arsenic $(\mathrm{P}=0.066)$, and the significant lower carbon content due to 
arsenic might be related to a lower photosynthetic activity (Mishra et al. 2014) and the lower chlorophyll content. After two weeks exposure, we observed no effects on leaf stoichiometry. Apparently, N:P molar ratios are relatively robust, as Li et al. (2015) reported similar values along a range of water depths for three common submerged macrophytes. Also other authors report a relative homeostasis of the $\mathrm{N}: \mathrm{P}$ ratio in aquatic plants irrespective of environmental nitrogen or phosphorus concentrations (Demars \& Edwards 2007; Güsewell \& Koerselman 2002). However, severe carbon stress due to very low $\mathrm{CO}_{2}$ (and $\mathrm{HCO}_{3}{ }^{-}$) availability as it occurs in the standard set-up of the M. spicatum sediment-water OECD test system (OECD 2014) where no aeration occurs and resulting pH values exceed 9 (EMG, pers. observ.), might modify plant stoichiometry. Nitrogen content in several Myriophyllum and other submerged macrophyte species was reduced under high $\mathrm{CO}_{2}$ availability, with $M$. spicatum exhibiting the lowest effects (Hussner et al., in press).

The principal component analysis revealed links between the different endpoints chosen in our study. All different treatment combinations were rather well separated along axes 1 and 2 . The separation of treatments along axis 1 was influenced by differences in arsenic concentration, separating between the two low ( 0 and $1.44 \mathrm{ppm}[\mathrm{As}])$ and the two high [7.2 and $36 \mathrm{ppm}[\mathrm{As}]$ ) concentrations. Differences based on $\mathrm{CO}_{2}$ availability showed along axis 2, but only for the two highest arsenic concentrations. Along axis 1, a high growth rate based on fresh mass corresponded to a high chlorophyll content, a high root mass and aboveground leaf mass fraction (RMF, LMF-a), and was opposed to higher stem mass fraction (SMF) and increases in all dry matter related endpoints (LDMC, RDMC, SDMC). We thus consider endpoints pointing to the left in the circle of correlation (Fig. 6B) reflecting active growth and development, while those pointing to the right as endpoints showing impaired growth. Interestingly, although we had not found many significant effects of $\mathrm{CO}_{2}$ availability on individual endpoints, treatments for one given arsenic level differed between 
high and low $\mathrm{CO}_{2}$ availability (HC, LC), with the strongest effect for $7.2 \mathrm{ppm}[\mathrm{As}]$ in sediment. Thus, low $\mathrm{CO}_{2}$ availability had not aggravated the impact of arsenic, but exerted different effects on the plants. These were a slight reduction in phosphorus content in leaves, modifications in the content of phenolic compounds (TPC) and the ratio of carotenoids to chlorophyll (car/chl), the latter two possible indicators of oxidative stress (Waśkiewicz et al. 2014).

\section{Conclusions}

This laboratory experiment combined realistic $\mathrm{CO}_{2}$ availability scenarios with presumed environmentally relevant arsenic exposure settings. Despite the high leaching of arsenic from the sediment to the water column, the effective concentrations for M. spicatum were in the range that can be found in areas with natural or anthropogenic high exposure to arsenic via sediment or water. We can thus partly confirm our first hypothesis that negative effects on growth and physiology can be observed at environmentally relevant arsenic concentrations. Our second hypothesis that low $\mathrm{CO}_{2}$ availability would aggravate the effects of arsenic could only partly be verified, but results might be different for a longer, chronic exposure or under more severe $\mathrm{CO}_{2}$ stress and $\mathrm{pH}$ values above 9 , as caused by the complete absence of aeration in the new OECD test guideline for M. spicatum (OECD 2014). With respect to our third hypothesis, we think that our experiment shows the complex response of M. spicatum to combined stressors. The combination of different endpoints allowed a rather clear distinction of treatment combinations. We suggest investigators consider whether a broader range of response variables can help identifying responses to stress-induced changes. Additional response variables may include plant traits such as biomass allocation, dry matter content, stoichiometry and the content in secondary metabolites in addition to general "endpoints" 
based on growth and pigment content. These additional endpoints might be useful in predicting the plant performance in an ecological context, as for example increased leaf biomass would result in better photosynthetic performance, or increased content in phenolic compounds could explain the plant's capacity to be defended against competitors or herbivores. Such effects on the "plant quality", i.e. the dry matter content, phenolic content or elemental stoichiometry, have already been shown to affect herbivory (Fornoff \& Gross 2014), and possibly other biotic interactions as allelopathy.

\section{Acknowledgment}

We greatly appreciate the help of P. Rousselle with the C:N analyses, J.-F. Poinsaint with setting up the experimental infrastructure, S. Devin and L. Minguez for statistical advice. AH benefited from an invitation by the UFR SciFa, Univ Lorraine for a visit of one month. AN was funded by a PhD stipend from the MESR, Ministère de l'Enseignement Supérieur et de la Recherche, France. The experiment was possible due to funding for the project "PICAI pollutant induced changes in allelochemical interactions" in the program ECODYN / EC2CO, INSU, CNRS to EMG and by support from the LTER - ZAM - Zone Atelier Moselle for AN, DP and EMG. We thank three anonymous reviewers and the editors of the special issue for constructive comments on prior versions of this manuscript.

\section{References}

AFNOR, 1990. Eaux-Méthodes d'Essais. Association Française de Normalisation (Ed.). ISBN 2-12$179041-1$

Cedergreen, N., J. C. Streibig \& N. H. Spliid, 2004. Sensitivity of aquatic plants to the herbicide metsulfuron-methyl. Ecotoxicology and Environmental Safety 57: 153-161. 
Demars, B. O. L. \& A. C. Edwards, 2007. Tissue nutrient concentrations in freshwater aquatic macrophytes: high inter-taxon differences and low phenotypic response to nutrient supply. Freshwater Biology 52: 2073-2086.

Dixon, R. A. \& N. L. Pavia, 1995. Stress-induced phenylpropanoid metabolism. Plant Cell 7: 10851097.

Dushenko, W. T., D. A. Bright \& K. J. Reimer, 1995. Arsenic bioaccumulation and toxicity in aquatic macrophytes exposed to gold-mine effluent: relationships with environmental partitioning, metal uptake and nutrients. Aquatic Botany 50: 141-158.

Elger. A. \& N.J. Willby, 2003. Leaf dry matter content as an integrative expression of plant palatability: the case of freshwater macrophytes. Functional Ecology 17: 58-65.

Eusebio Malheiro, A. C., P. Jahns \& A. Hussner, 2013. $\mathrm{CO}_{2}$ availability rather than light and temperature determines growth and phenotypical responses in submerged Myriophyllum aquaticum. Aquatic Botany 110: 31-37.

Finnegan, P. M. \& W. Chen, 2012. Arsenic toxicity: The effects on plant metabolism. Frontiers in Physiology 3: 182

Fornoff, F. \& E. M. Gross, 2014. Induced defense mechanisms in an aquatic angiosperm to insect herbivory. Oecologia 175: 173-185.

Geng, C. N., Y. G. Zhu, W. J. Liu \& S. E. Smith, 2005. Arsenate uptake and translocation in seedlings of two genotypes of rice is affected by external phosphate concentrations. Aquatic Botany 83: 321-331.

Grace, J. B. \& R. G. Wetzel, 1978. The production biology of Eurasian watermilfoil (Myriophyllum spicatum L.): a review. Joural of Aquatic Plant Management 16: 1-11.

Gross, E. M., 2003. Differential response of tellimagrandin II and total bioactive hydrolysable tannins in an aquatic angiosperm to changes in light and nitrogen. Oikos 103: 497-504.

Gross, E. M. \& E. S. Bakker, 2012. The role of plant secondary metabolites in freshwater macrophyteherbivore interactions: Limited or unexplored chemical defences? In Iason, G. R., M. Dicke \& 
S. E. Hartley (eds.) The Integrative Role of Plant Secondary Metabolites in Ecological Systems. British Ecological Society / Cambridge University Press, Sussex, UK, pp. 154-169.

Guo, H. M., Z. N. Zhong, M. Lei, X. L. Xue, X. M. Wan, J. Y. Zhao \& T. B. Chen, 2012. Arsenic uptake from arsenic-contaminated water using hyperaccumulator Pteris vittata L.: Effect of chloride, bicarbonate, and arsenic species. Water Air and Soil Pollution 223: 4209-4220.

Güsewell, S. \& M. Koerselman, 2002. Variation in nitrogen and phosphorus concentrations of wetland plants. Perspectives in Plant Ecology Evolution and Systematics 5: 37-61.

Harguinteguy, C. A., M. L. Pignata \& A. Fernández-Cirelli, 2015. Nickel, lead and zinc accumulation and performance in relation to their use in phytoremediation of macrophytes Myriophyllum aquaticum and Egeria densa. Ecological Engineering 82: 512-516.

Hartley, S. E., C. G. Jones, G. C. Couper \& T. H. Jones, 2000. Biosynthesis of plant phenolic compounds in elevated atmospheric $\mathrm{CO}_{2}$. Global Change Biology 6: 497-506.

Hussner, A., D. Hofstra, P. Jahns \& J. Clayton, 2015. Response capacity to $\mathrm{CO}_{2}$ depletion rather than temperature and light effects explain the growth success of three alien Hydrocharitaceae compared with native Myriophyllum triphyllum in New Zealand. Aquatic Botany 120: 205211.

Hussner, A. \& P. Jahns, 2015. European native Myriophyllum spicatum showed a higher use capacity than alien invasive Myriophyllum heterophyllum. Hydrobiologia 746: 171-182.

Hussner, A., T. Mettler-Altmann, A. P. M. Weber \& K. Sand-Jensen, in press. Acclimation of photosynthesis to supersaturated $\mathrm{CO}_{2}$ in aquatic plant bicarbonate users. Freshwater Biology, accepted manuscript. doi:10.1111/fwb.12812

Krayem M, V Deluchat, M. Rabiet, K. Cleries, J. F. Lenain, Z. Saad, V. Kazpard \& P. Labrousse, 2016. Effect of arsenate As(V) on the biomarkers of Myriophyllum alterniflorum in oligotrophic and eutrophic conditions. Chemosphere 147: 131-137.

Lavid, N., A. Schwartz, O. Yarden \& E. Tel-Or, 2001. The involvement of polyphenols and peroxidase activities in heavy-metal accumulation by epidermal glands of the waterlily (Nymphaeaceae). Planta 212: 323-331. 
Lê, S., J. Josse \& F. Husson, 2008. FactoMineR: An R Package for Multivariate Analysis. Journal of Statistical Software. 25: 1-18.

Leao GA, JA de Oliveira, RTA Felipe, FS Farnese \& GS Gusman, 2014. Anthocyanins, thiols, and antioxidant scavenging enzymes are involved in Lemna gibba tolerance to arsenic. Journal of Plant Interactions 9: 143-151.

Leu, E., A. Krieger-Liszkay, C. Goussias \& E. M. Gross, 2002. Polyphenolic allelochemicals from the aquatic angiosperm Myriophyllum spicatum L. inhibit photosystem II. Plant Physiology 130: 2011-2018.

Li, W., T. Cao, L. Y. Ni, G. R. Zhu, X. L. Zhang, H. Fu, X. Song \& P. Xie, 2015. Size-dependent C, N and P stoichiometry of three submersed macrophytes along water depth gradients. Environmental Earth Sciences 74: 3733-3738.

Lichtenthaler, H. K. \& C. Buschmann, 2001. Chlorophylls and Carotenoids: Measurement and Characterization by UV-VIS Spectroscopy Current Protocols in Food Analytical Chemistry. John Wiley \& Sons, Inc.

Meybeck, M., 2004. The global change of continental aquatic systems: Dominant impacts of human activities Water Science and Technology 49: 73-83.

Mishra, S., H. J. Stark \& H. Kupper, 2014. A different sequence of events than previously reported leads to arsenic-induced damage in Ceratophyllum demersum L. Metallomics 6: 444-454.

Mkandawire, M. \& E. G. Dudel, 2012. Homeostatic regulation of elemental stoichiometry by Lemna gibba L. G3 when nutrient interact with toxic metals. Ecotoxicology 21: 456-464.

Murray, J. R. \& W. P. Hackett, 1991. Dihydroflavonol reductase activity in relation to differential anthocyanin accumulation in juvenile and mature phase Hedera helix L. Plant Physiology $97: 343-351$

Nuttens, A., S. Chatellier, S. Devin, C. Guignard, A. Lenouvel \& E. M. Gross, 2016. Does nitrate copollution affect biological responses of an aquatic plant to two common herbicides? Aquatic Toxicology 177: 355-364. 
OECD, 2014. TG 239: Water-sediment Myriophyllum spicatum toxicity test. Test Guideline No. 239, $23 \mathrm{pp}$.

Pérez-Harguindeguy, N., S. Díaz, E. Garnier, S. Lavorel, H. Poorter, P. Jaureguiberry, M. S. BretHarte, W. K. Cornwell, J. M. Craine, D. E. Gurvich, C. Urcelay, E. J. Veneklaas, P. B. Reich, L. Poorter, I. J. Wright, P. Ray, L. Enrico, J. G. Pausas, A. C. de Vos, N. Buchmann, G. Funes, F. Quétier, J. G. Hodgson, K. Thompson, H. D. Morgan, H. ter Steege, M. G. A. van der Heijden, L. Sack, B. Blonder, P. Poschlod, M. V. Vaieretti, G. Conti, A. C. Staver, S. Aquino \& J. H. C. Cornelissen, 2013. New handbook for standardised measurement of plant functional traits worldwide. Australian Journal of Botany 61: 167-234.

R Studio Team, 2015. RStudio: Integrated Development for R. RStudio, Inc., Boston, MA, USA.

Rahman, M. A., H. Hasegawa \& R. P. Lim, 2012. Bioaccumulation, biotransformation and trophic transfer of arsenic in the aquatic food chain. Environmental Research 116: 118-135.

Reznik, H. \& R. Neuhausel, 1959. Farblose Anthocyane bei submersen Wasserpflanzen. Zeitschrift für Botanik 47: 471-489.

Robinson, B., N. Kim, M. Marchetti, C. Moni, L. Schroeter, C. van den Dijssel, G. Milne \& B. Clothier, 2006. Arsenic hyperaccumulation by aquatic macrophytes in the Taupo Volcanic Zone, New Zealand. Environmental and Experimental Botany 58: 206-215.

Sánchez-Viveros, G., R. Ferrera-Cerrato \& A. Alarcón, 2011. Short-term effects of arsenate-induced toxicity on growth, chlorophyll and carotenoid contents, and total content of phenolic compounds of Azolla filiculoides. Water Air Soil Pollution 217: 455-462.

Segner, H., M. Schmitt-Jansen \& S. Sabater, 2014. Assessing the impact of multiple stressors on aquatic biota: The receptor's side matters. Environmental Science \& Technology 48: 76907696.

Smart, R. M. \& J. W. Barko, 1985. Laboratory culture of submersed freshwater macrophytes on natural sediments. Aquatic Botany 21: 251-263.

Smedley, P. L. \& D. G. Kinniburgh, 2002. A review of the source, behaviour and distribution of arsenic in natural waters. Applied Geochemistry 17: 517-568. 
650 Smith, C. S. \& J. W. Barko, 1990. Ecology of Eurasian watermilfoil. Journal of Aquatic Plant Management 28: 55-64.

652

653

654

655

656

657

658

659

660

Taggart, M. A., R. Mateo, J. M. Charnock, F. Bahrami, A. J. Green \& A. A. Meharg, 2009. Arsenic rich iron plaque on macrophyte roots - an ecotoxicological risk? Environmental Pollution 157: 946-954.

Tripathi, R. D., P. Tripathi, S. Dwivedi, A. Kumar, A. Mishra, P. S. Chauhan, G. J. Norton \& C. S. Nautiyal, 2014. Roles for root iron plaque in sequestration and uptake of heavy metals and metalloids in aquatic and wetland plants. Metallomics 6: 1789-1800.

Waśkiewicz, A., M. Beszterda \& P. Goliński, 2014. Nonenzymatic Antioxidants in Plants. In:

Oxidative Damage to Plants: Antioxidant Networks and Signaling (ed. P. Ahmad). pp. 201234. 
Table 1: Recovery of arsenic at the end of the experiment in the different treatments. Data represent means \pm 1 SE; $n=4$.

\section{Recovery}

$\begin{array}{cc}\text { Treat- } & \begin{array}{c}\text { Nominal sediment } \\ \text { ment }\end{array} \\ & \text { As concentration } \\ {\left[\mathrm{mg} \mathrm{kg}^{-1}\right]}\end{array}$

HC

1.44
7.20
36.00

LC

0
1.44
7.20
36.00

\section{$\%$ of total $\%$ recovery of \\ recovery found in initially applied [As]}

\begin{tabular}{|c|c|c|c|c|}
\hline $\begin{array}{l}\text { Sediment } \\
{\left[\mathrm{mg} \mathrm{kg}^{-1}\right]}\end{array}$ & $\begin{array}{l}\text { Water } \\
{\left[\mu \mathrm{g} \mathrm{l}^{-1}\right]}\end{array}$ & Sediment & Water & \\
\hline $0.88 \pm 0.14$ & $2.75 \pm 0.75$ & 96.3 & 3.7 & \\
\hline $1.45 \pm 0.12$ & $50.50 \pm 5.85$ & 69.9 & 30.1 & $145.0 \pm 6.6$ \\
\hline $3.60 \pm 0.43$ & $344.75 \pm 25.96$ & 45.6 & 54.4 & $110.0 \pm 7.4$ \\
\hline $8.67 \pm 0.60$ & $2196.75 \pm 226.01$ & 24.5 & 75.5 & $100.4 \pm 8.0$ \\
\hline $0.64 \pm 0.79$ & $16.50 \pm 3.43$ & 44.4 & 55.6 & \\
\hline $1.63 \pm 0.16$ & $52.0 \pm 6.76$ & 71.5 & 28.5 & $158.4 \pm 10.4$ \\
\hline $2.89 \pm 0.15$ & $260.50 \pm 25.01$ & 47.4 & 52.6 & $85.4 \pm 4.1$ \\
\hline $7.20 \pm 0.67$ & $1618.75 \pm 344.10$ & 28.1 & 71.9 & $76.2 \pm 12.6$ \\
\hline
\end{tabular}


664 Table 2: 2-way ANOVA results based on the fixed factors carbon and arsenic. Shown are the 665 effect of $\mathrm{CO}_{2}$ availability and arsenic pollution on different response variables measured in 666 Myriophyllum spicatum. Results are based a) on growth data for both shoots per microcosm, 667 b) on plant traits and metabolism of leaves from shoot A and c) on the stoichiometry of the 668 whole shoot B. Degrees of freedom: $d f=1$ for carbon, $\mathrm{df}=3$ for arsenic; $\mathrm{df}=3$ for carbon $\mathrm{x}$ 669 arsenic. * $\log$ transformed data. ** $1 / \mathrm{x}$ transformed data. Bold numbers indicate significant 670 results $(\mathrm{P}<0.05)$. Marginally significant results $(\mathrm{P}<0.1)$ are marked in italics.

671 RGR - Relative growth rate based on $\mathrm{dm}$ - dry mass, fm - fresh mass or L - length. DMC 672 Dry matter content. LMF and LMF-a - leaf mass fraction based on total biomass or 673 aboveground biomass. SMF, RMF - stem and root mass fractions. LDMC, SDMC and 674 RDMC - leaf, stem and root dry matter content. Chl - chlorophyll. Car - carotenoids. TPC 675 total phenolic compounds. $\mathrm{C}$ - carbon. $\mathrm{N}$ - nitrogen. $\mathrm{P}$ - phosphorus.

\section{Carbon \\ $\mathrm{F}$ \\ Arsenic \\ $\mathrm{F}$}

A) Growth rate and dry matter content of both shoots

\section{RGR-dm}

RGR-fm

RGR-L

DMC

B1) Plant traits of shoot A

$\begin{array}{lr}\text { LMF** } & 5.415 \\ \text { LMF-a } & 13.335 \\ \text { SMF } & 12.329 \\ \text { RMF } & 0.309 \\ \text { LDMC } & 0.026 \\ \text { SDMC } & 0.512 \\ \text { RDMC* } & 24.906\end{array}$

B2) Pigments in leaves of shoot $A$

$\begin{array}{lr}\text { Chl } a & 1.064 \\ \text { Chl } b & 3.375 \\ \text { Chl } a \& b & 1.768 \\ \text { Chl } a / b \text { ratio } & 3.643 \\ \text { Car } & 3.462 \\ \text { Car/chl ratio } & 20.639 \\ \text { Anthocyanins } & 1.977 \\ \text { TPC } & 576.87\end{array}$

C1) Plant stoichiometry of leaves from shoot $A$

$\begin{array}{lll}\mathrm{C} & 0.934 & 0.346 \\ \mathrm{~N} & 1.258 & 0.273 \\ \mathrm{P} & 3.093 & 0.091 \\ \mathrm{CN} & 1.284 & 0.268 \\ \mathrm{CP} & 2.080 & 0.162 \\ \mathrm{NP} & 0.919 & 0.347\end{array}$

C2) Plant stoichiometry of shoot B

$\begin{array}{ll}\mathrm{C} & 5.848 \\ \mathrm{~N} & 0.164 \\ \mathrm{P} & 2.837 \\ \mathrm{CN} & 0.013 \\ \mathrm{CP} & 6.196 \\ \mathrm{NP} & 5.343\end{array}$

5.366

42.95

15.590

27.831

$\mathbf{0 . 0 1 3}$

0.029

0.001

0.002

0.583

0.874

0.481

$<0.001$

\subsection{3}

0.079

0.196

0.068

0.075

$<0.001$

0.173

$<0.001$

\section{$\mathbf{0 . 0 2 4}$}

0.689

0.105

0.910

0.020

0.030

\subsection{0}

13.249

32.794

36.651

17.030

48.158

49.897

10,755

9.630

10.744

0.341

2.718

6.572

4.991

43.03

6.610

2.730

0.825

1.652

1.146

1.554

0.573

5.518

3.808

6.366

4.722

1.053
Carbon x Arsenic

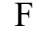

$P$

$\begin{array}{lll}<\mathbf{0 . 0 0 1} & 1.683 & 0.197\end{array}$

$\begin{array}{lll}<\mathbf{0 . 0 0 1} & 2.365 & 0.096\end{array}$

$\begin{array}{lll}<\mathbf{0 . 0 0 1} & 1.779 & 0.178\end{array}$

$\begin{array}{lll}\mathbf{0 . 0 3 0} & 0.396 & 0.757\end{array}$

$\begin{array}{lll}<\mathbf{0 . 0 0 1} & 1.278 & 0.304\end{array}$

$<\mathbf{0 . 0 0 1} \quad 1.065 \quad 0.382$

$\begin{array}{lll}<\mathbf{0 . 0 0 1} & 0.242 & 0.866\end{array}$

$\begin{array}{lll}<\mathbf{0 . 0 0 1} & 2.281 & 0.105\end{array}$

$\begin{array}{lll}<0.001 & 3.358 & \mathbf{0 . 0 3 6}\end{array}$

$\begin{array}{lll}<\mathbf{0 . 0 0 1} & 1.478 & 0.246\end{array}$

$\begin{array}{lll}<\mathbf{0 . 0 0 1} & 2.206 & 0.114\end{array}$

$\begin{array}{lll}<\mathbf{0 . 0 0 1} & 1.870 & 0.162\end{array}$

$\begin{array}{lll}<\mathbf{0 . 0 0 1} & 2.109 & 0.126\end{array}$

$\begin{array}{lll}0.796 & 1.535 & 0.231\end{array}$

$0.067 \quad 9.629<\mathbf{0 . 0 0 1}$

$\mathbf{0 . 0 0 2} \quad 9.489<\mathbf{0 . 0 0 1}$

$\begin{array}{lll}0.008 & 2.782 & 0.063\end{array}$

$\begin{array}{lll}<\mathbf{0 . 0 0 1} & 28.16 \quad<\mathbf{0 . 0 0 1}\end{array}$

$\begin{array}{lll}\mathbf{0 . 0 0 2} & 0.997 & 0.411\end{array}$

$\begin{array}{lll}0.066 & 1.784 & 0.177\end{array}$

$\begin{array}{lll}0.493 & 0.407 & 0.749\end{array}$

$\begin{array}{lll}0.204 & 1.680 & 0.198\end{array}$

$\begin{array}{lll}0.351 & 0.441 & 0.726\end{array}$

$\begin{array}{lll}0.226 & 0.233 & 0.872\end{array}$

$\begin{array}{lll}0.638 & 7.242 & \mathbf{0 . 0 0 1}\end{array}$

$\begin{array}{lll}0.005 & 2.302 & 0.101\end{array}$

$\begin{array}{lll}\mathbf{0 . 0 2 3} & 2.988 & 0.051\end{array}$

$\begin{array}{lll}\mathbf{0 . 0 0 3} & 1.040 & 0.393\end{array}$

$\begin{array}{lll}\mathbf{0 . 0 1 0} & 2.510 & 0.083\end{array}$

$\begin{array}{lll}0.387 & 0.787 & 0.513\end{array}$ 
679

680

681

682

683

684

685

686

687

688

689

690

691

692

693

694

695

696

697

698

699

700

Fig. 1. Effect of arsenic and $\mathrm{CO}_{2}$ availability $\left(\mathrm{HC}-\right.$ high $\mathrm{CO}_{2} ; \mathrm{LC}-$ low $\left.\mathrm{CO}_{2}\right)$ on the relative growth rate of Myriophyllum spicatum based on dry mass (RGR-dm; A) or total shoot length (RGR-L; B) and the dry matter content (DMC; C). Results are based on data for both shoots A and B used per replicate, and represent means \pm 1 SE from $n=4$. Results from the Tukey post-hoc tests following the 2-way ANOVA are shown as small letter code next to each treatment. If no letters are shown for a response variable, treatments were not different to each other. Note that y-axes do not start with zero but are adapted to the data range.

Fig. 2. Effect of arsenic and $\mathrm{CO}_{2}$ availability $\left(\mathrm{HC}-\right.$ high $\mathrm{CO}_{2} ; \mathrm{LC}-$ low $\left.\mathrm{CO}_{2}\right)$ on plant traits, here the biomass allocation to leaves, stems and roots (LMF, SMF, RMF). The proportion of leaves on the total aboveground biomass is shown as LMF-a. Results are based on data for shoots $\mathrm{A}$, and represent means $\pm 1 \mathrm{SE}$ from $\mathrm{n}=4$. Results from the Tukey post-hoc tests following the 2-way ANOVA are shown as small letter code next to each treatment. If no letters are shown for a response variable, treatments were not different to each other. Note that y-axes do not start with zero but are adapted to the data range.

Fig. 3. Effect of arsenic and $\mathrm{CO}_{2}$ availability $\left(\mathrm{HC}-\right.$ high $\mathrm{CO}_{2} ; \mathrm{LC}-$ low $\left.\mathrm{CO}_{2}\right)$ on leaf pigments and relevant pigment ratios. A - Total chlorophyll content. B - Carotenoid content. $\mathrm{C}$ - Chlorophyll a/b (chl a/b) ratio. D - Carotenoid/total chlorophyll ratio (Car/chl ratio). Results are based on data for leaves from shoot $A$, and represent means \pm 1 SE from $n=4$. Results from the Tukey post-hoc tests following the 2-way ANOVA are shown as small letter code next to each treatment. If no letters are shown for a response variable, treatments were not different to each other. Note that y-axes do not start with zero but are adapted to the data range. 
Fig. 4. Effect of arsenic and $\mathrm{CO}_{2}$ availability $\left(\mathrm{HC}-\right.$ high $\mathrm{CO}_{2} ; \mathrm{LC}-$ low $\left.\mathrm{CO}_{2}\right)$ on leaf phenolic compounds, here content in anthocyanins (A) and total phenolic compounds (TPC; B). Results are based on data for leaves from shoot A, and represent means \pm 1 SE from $n=4$. Results from the Tukey post-hoc tests following the 2-way ANOVA are shown as small letter code next to each treatment. If no letters are shown for a response variable, treatments were not different to each other. Note that y-axes do not start with zero but are adapted to the data range.

Fig. 5. Effect of arsenic and $\mathrm{CO}_{2}$ availability $\left(\mathrm{HC}-\right.$ high $\mathrm{CO}_{2} ; \mathrm{LC}-$ low $\left.\mathrm{CO}_{2}\right)$ on elemental composition, (panels A - C: Content in carbon $-\mathrm{C}$; nitrogen $-\mathrm{N}$; phosphorus $-\mathrm{P}$ ) and resulting molar ratios (leaf stoichiometry; molar ratios of panels D - F: C:N, C:P and N:P). Results are based on data for leaves from shoots A and represent means \pm 1 SE from $n=4$. Results from the Tukey post-hoc tests following the 2-way ANOVA are shown as small letter code next to each treatment. If no letters are shown for a response variable, treatments were not different to each other. Note that y-axes do not start with zero but are adapted to the data range.

Fig. 6. Principal component analysis of the response of Myriophyllum spicatum to increasing concentrations of arsenate in sediment $\left(0,1.44,7\right.$ and $\left.36 \mathrm{mg} \mathrm{kg}^{-1}\right)$, cultivated either in high or low $\mathrm{CO}_{2}$ availability (HC, $\left.\mathrm{LC}\right)$, and after 14 days of exposure. A) Correlation circle showing vectors for all measured endpoints (except DMC of whole shoots) as shown in Table 2 (see list of abbreviations, aty - anthocyanins). B) PCA for all different treatment combinations. Axes 1 and 2 explained 37.2 and $15.7 \%$ of the total inertia. 

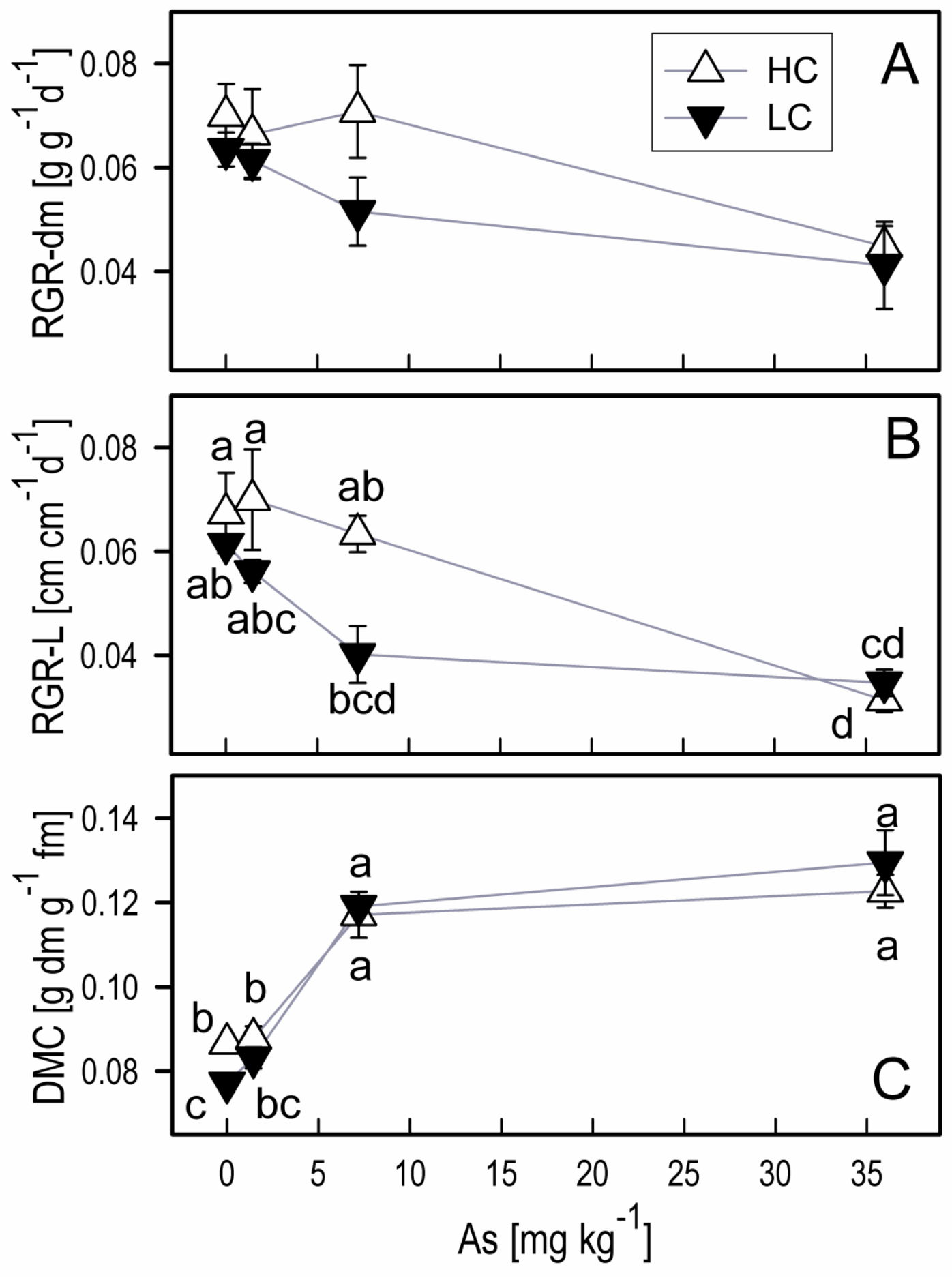
Fig. 2
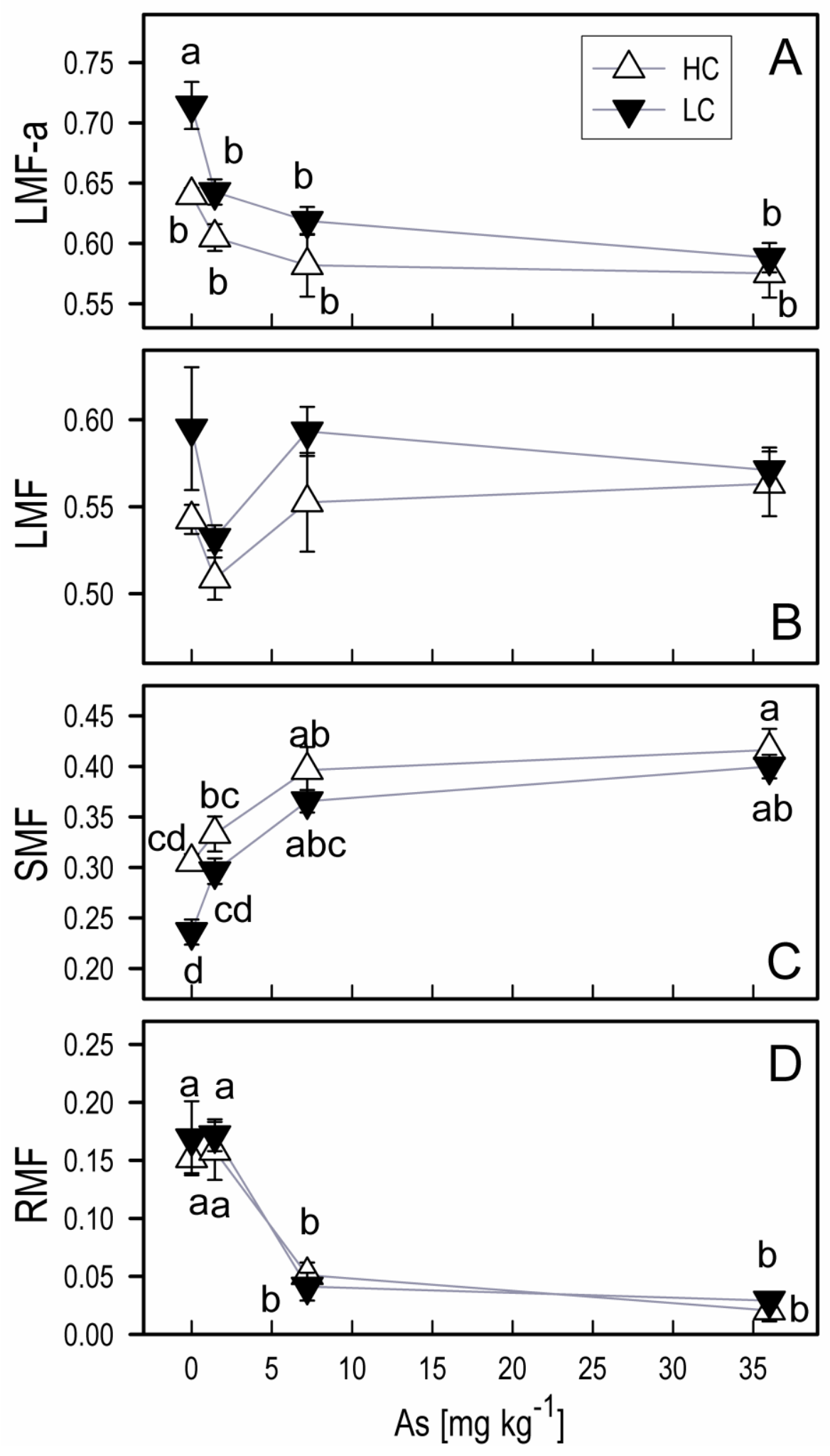
Fig. 3
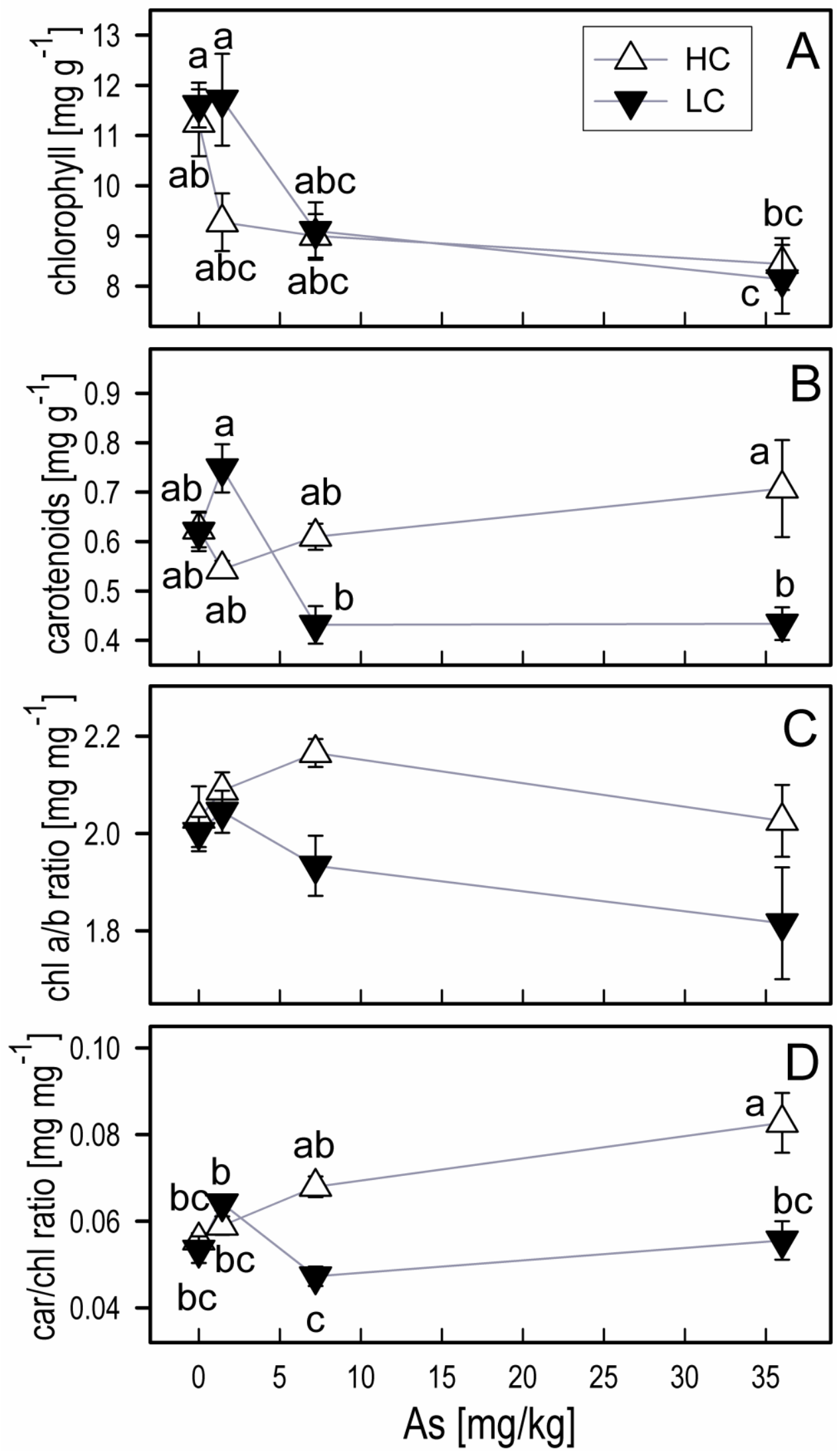
733 Fig. 4
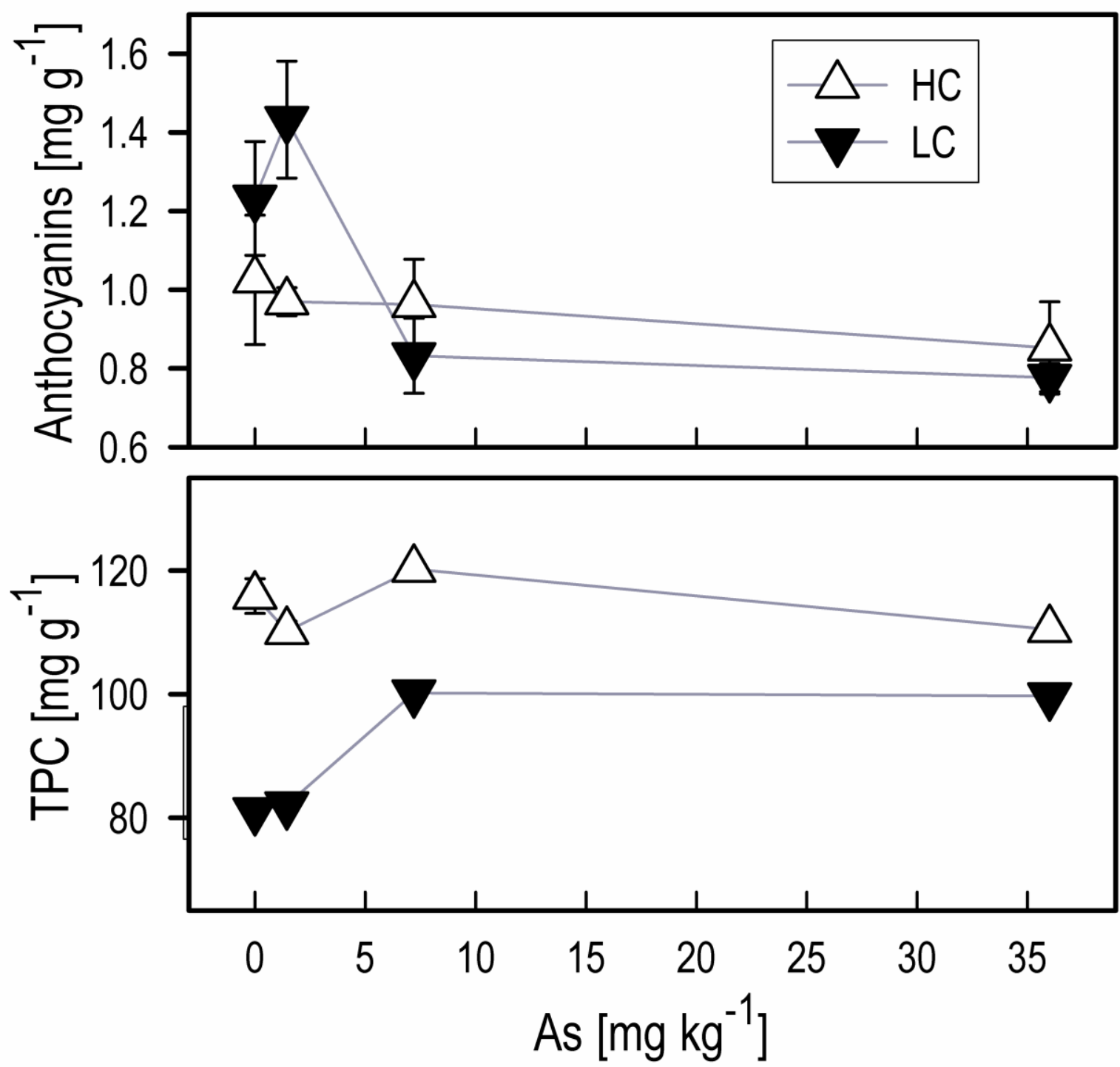
Fig. 5
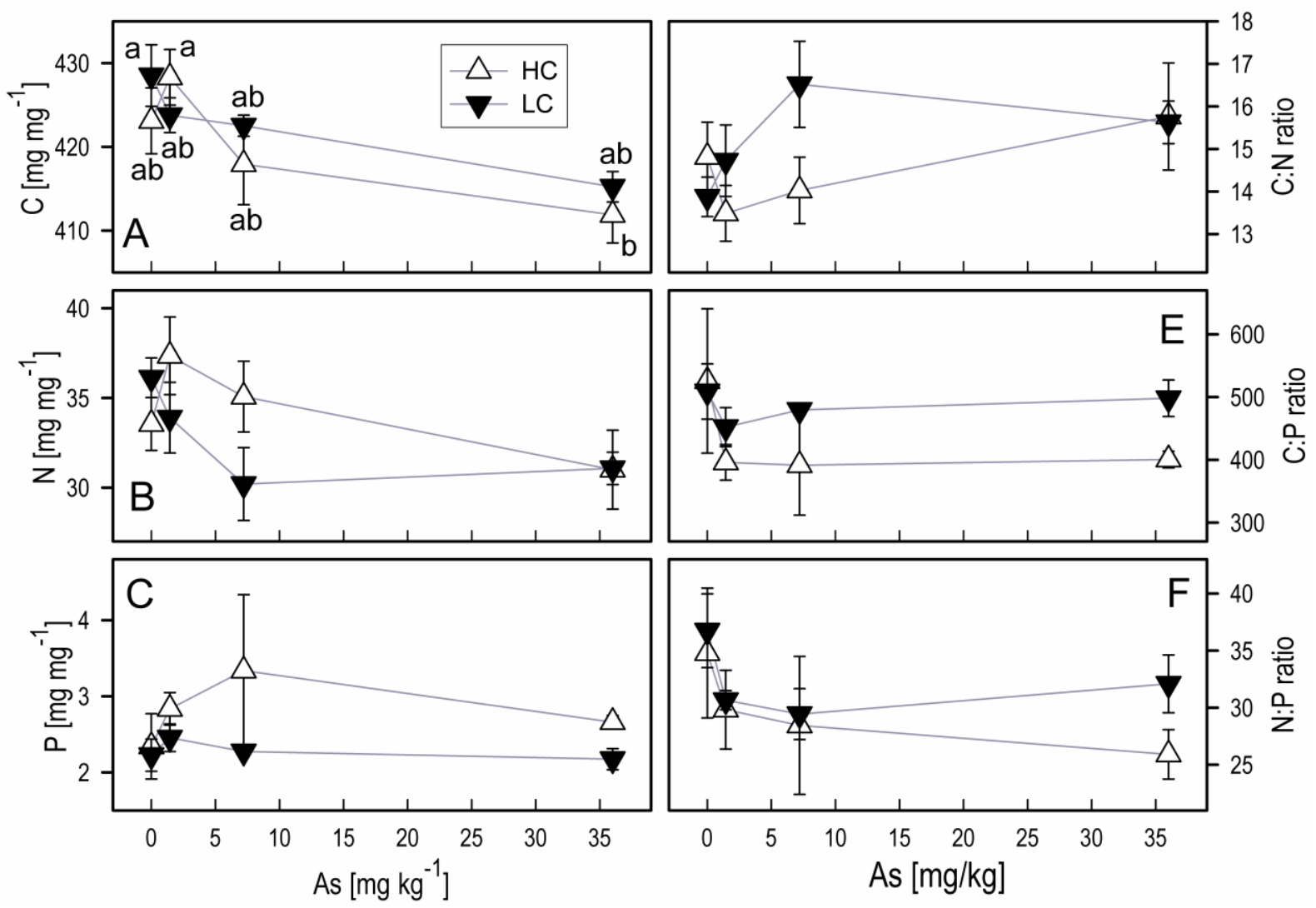

737 As [mg kg ${ }^{-1}$ ] 
Fig. 6

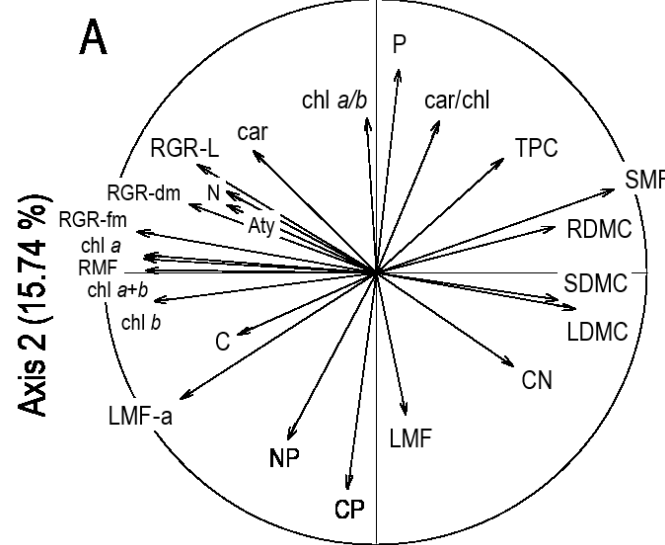

Axis $1(37.24 \%)$

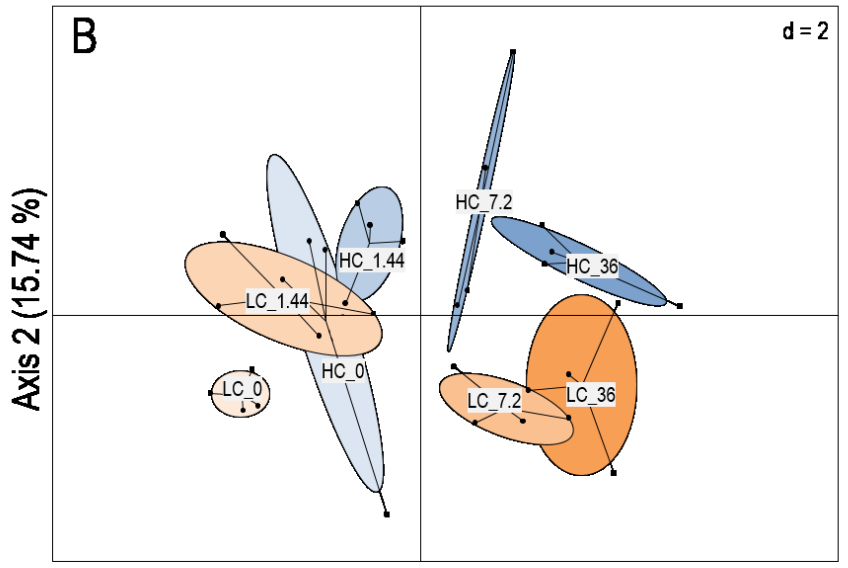

Axis 1 (37.24 \%) 